
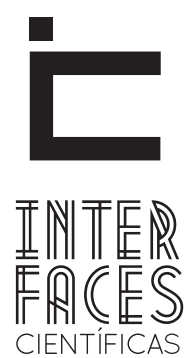

EDUCAÇ̃̃o

ISSN IMPRESSO 2316-333X

ISSN ELETRÔNICO 2316-3828

Dossiê

\title{
ASSISTÊNCIA PÚBLICA ESCOLAR PARA CRIANÇAS E JOVENS DESVALIDOS NO BRASIL DA PRIMEIRA REPÚBLICA'
}

Maria Zélia Maia de Souza ${ }^{1}$

\section{RESUMO}

Em pleno século XXI é comum o transeunte das ruas cariocas deparar-se com crianças e jovens abandonados perambulando com cobertores sobre as suas costas. É fato notório que essa condição social não é exclusividade da cidade do Rio de Janeiro. Entretanto, esse fenômeno social - crianças abandonadas não é natural e sim produção de uma sociedade que possui ambiguidades, ou seja, que abandona, mas que também acolhe. É nesta tensão que inicio a presente reflexão que tem por objetivo analisar o Instituto Profissional João Alfredo (IPJA) e a Casa de São José/Instituto Ferreira Vianna. Estas instituições asilares/escolares, mantidas pelo poder público do Distrito Federal na Primeira República, foram exemplos de assistência pela profissionalização à criança e ao jovem pobres. Trata-se ainda de demonstrar um modo peculiar de organização de proteção ao referido grupo social, ou seja, por meio de instituições que acumularam as funções de asilo e de educação escolar.

\section{PALAVRAS-CHAVE}

Assistência. Educação. Crianças. Jovens. Desvalidos. 


\section{ABSTRACT}

This article discusses the State presence in the Government of childhood, the quantification of poor childhood strategies and the creation of educational institutions for a specific audience. Take as a reference the Instituto Profissional João Alfredo and the Casa de São José/Instituto Ferreira Vianna as concrete examples of assistance for the professionalization of poor children and the young people in the city of Rio de Janeiro, in the times first Republic days. The text explores the intersection between these two institutions. Therefore, the focus of the study are these institutions in the context of the process of modernization of the Capital City. The study aims to understand a peculiar mode of organization of assistance for the professionalization, namely the functioning of institutions that have accumulated the functions of asylum and school education.

\section{KEYWORDS}

Assistance. Education. Children. Youth. Helpless.

\section{RESUMEN}

Este artículo aborda la presencia del estado en el gobierno de la infancia, la cuantificación de las estrategias de la infancia pobre y la creación de instituciones educativas para un público específico. Tomar como referencia el Instituto profesional João Alfredo y la Casa de São José/Instituto Ferreira Vianna como ejemplos concretos de la ayuda para la profesionalización de los niños y los jóvenes pobres en la ciudad de Rio de Janeiro, en los tiempos de la primera República. El texto explora la intersección entre estas dos instituciones para el enfoque del estudio son estas institu-

ciones en el contexto del proceso de modernización de la ciudad Capital. El estudio pretende entender un peculiar modo de organización de la asistencia para la profesionalización, es decir, el funcionamiento de las instituciones que se han acumulado las funciones del asilo y escuela de educación.

\section{PALABRAS CLAVE}

Asistencia. Educación. Niños. Jóvenes. Desfavorecidos. 


\section{POBREZA COMO UM PROBLEMA DE GOVERNO}

Em 1911, um requerimento à matrícula no IPJA continha os seguintes dizeres:

\begin{abstract}
Exm $^{\circ} \mathrm{Sn}$. Dr. Prefeito do Districto Federal
Frederico de Santiago padrinho e protetor do menor Renato Correio Santos Roxo desejando encaminhar e assegurar o futuro do dito menor com uma profissão, e existindo um estabelecimento amparador nesta capital, que é o Instituto Profissional [João Alfredo], sob a guarda de $V^{a}$. Ex ${ }^{a}$. o suplicante e confiante nos seus sentimentos humanitários e justiça de Va. Exa ${ }^{a}$. vem respeitosamente pedir-lhe a matricula [...]

Pede deferimento. Rio de Janeiro, 16 de março de 1911.

Frederico de Santiago (Pasta RCR 021, 1911, AAMD).
\end{abstract}

Em outro requerimento, do ano de 1919, o bacharel Luiz de Souza Dias assim argumentava a respeito das dificuldades enfrentadas por sua família:

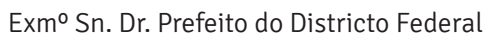

O bacharel Luiz de Souza Dias, diplomado em Sciencias Jurídicas e Sociais, tendo soffrido, há 5 annos, um insulto apopléctico, ficou desde então hemiplégico, impossibilitado de exercer a sua profissão de advogado. Tendo numerosa família e achando-se em condições de, por extrema pobreza, não poder educar os seus filhos, dando-lhes a instrucção de que carecem, pede que $V^{a}$. Exa . admita um d'elles gratuitamente, 0 de nome Antonio com 12 annos de edade, no Instituto Profissional João Alfredo, ou em outro mantido pelos cofres municipaes do Districto Federal.

Em taes termos, o Supplicante pede deferimento.

E.R.M. Niteroy, 09 de outubro de 1919. Luiz de Souza Dias (Pasta OCC 084, 1920, AAMD)

Não apenas nesses, mas nos diversos requerimentos a que tive acesso observa-se a recorrência de relatos acerca da situação de pobreza dos responsáveis pelos menores pobres candidatos à matrícula no IPJA. Nesse sentido, esses requerimentos nos possibilitam indagar sobre a relação entre situação de pobreza e demanda por profissionalização de crianças no contexto urbano.
Também no cotidiano social em geral, o que ocorre é a estigmatização dos grupos pobres, imprimindo-lhes uma condição de inferioridade social. Dessa maneira, a criação de instituições destinadas à educação de pobres é parte do contexto que busca minimizar os efeitos da pobreza na sociedade. Haja vista que educar os jovens para serem "uteis à si e à sua pátria" foi um lema recorrentemente usado pelos poderes públicos.

Cabe ressaltar que diferentes autores vêm destacando o processo histórico de desenvolvimento das preocupações dos adultos em relação às crianças, tanto do ponto de vista do cuidado e proteção como no aspecto pedagógico (Veiga, 2007; Gondra, 2000; Rizzini, 2006; Gouveia, 2006, Schueler, 1999). No caso das crianças pobres, também foi recorrente a associação entre educação e trabalho, sendo que esta associação "parece ter sido uma fórmula amplamente difundida no Ocidente, marcando experiências no velho e novo continente, nas metrópoles e jovens nações (GONDRA \& SCHUELER, 2008, p. 108). Dessa forma, a partir do momento que a criança passou a ser representada como a "sementeira do porvir" (GONDRA, 2000), a problemática da proteção demandou a criação de uma série de associações e instituições para cuidar da criança (KUHLMANN Jr., 2002, p. 464).

Nesse cenário, observa-se a crescente participação do Estado nas questões de proteção aos menos favorecidos, ainda no período colonial, com as Ordenações Filipinas, inclusive com vigência durante o período pós-independência. No período imperial, além das Ordenações Filipinas, outras normalizações se fizeram para a proteção das crianças desvalidas. Este é o caso da Reforma do ensino Primário e Secundário da Corte de 1854, elaborada por Couto Ferraz, na tentativa de resolução dos problemas da infância desvalida na cidade do Rio de Janeiro. Embora tenha sido uma reforma para o ensino público, o autor a apresenta como parte da política de assistência para criança desvalida. Por essa reforma Couto Ferraz estabeleceu nos artigos 62 e 63 a instrução primária associada ao ensino de ofícios em estabelecimentos que conju- 
gassem as funções de asilo e de escola primária de ensino profissional para meninos desvalidos. Portanto, indícios de que o Estado organizou-se com vistas a gerir riscos, ou seja, preparar o futuro da infância desvalida significava, para Couto Ferraz, diminuir os custos futuros da política social.

Assim, desde fins do século XIX, observa-se o crescimento de ações para o trato da criança desvalida. Um conjunto de acontecimentos que estavam em curso, como a industrialização, a urbanização, as mudanças nas relações de trabalho, possibilitaram a emergência da forma racionalizada de pensar a assistência estatal, que, foram tanto de ordem civil quanto militares (CUNHA, 2007; LIMA, 2013). Desse modo, nota-se que essas formas de proteção mantiveram-se bastante heterogêneas, tanto as ações de ordem do governo geral quanto aquelas promovidas pelos governos locais.

Em tempo, convém mencionar que, nos anos iniciais da Primeira República, a referência ao problema da criança desvalida é recorrente, não somente na cidade do Rio de Janeiro. A propósito, o político e jornalista Quintino Bocaiúva (1836-1912), enquanto presidente do Estado do Rio de Janeiro (1900-1903), afirmava que

\begin{abstract}
A massa da população não deve permanecer mergulhada nas trevas da ignorância. [...] Ao mais superficial e desattento observador impressiona o numero considerável de meninos vadios, abandonados da solicitude paterna, pela pobreza, pela inconsciencia de seu dever, ou pelo relaxamento, desde a mais tenra infância aos vícios próprios dos adultos e os defeitos inherentes á ausência de qualquer educação (BOCAIÚVA, In: Relatório do Presidente da Província do Rio de Janeiro do ano de 1902).
\end{abstract}

Assim, Quintino Bocaiúva discursava para a Câmara dos Deputados no sentido de mobilizar outros políticos para o problema do analfabetismo da grande maioria da população, bem como acerca do problema das crianças abandonadas. Inclusive, o excerto apresentado acima nos aproxima da noção de Estado pro- tetor/providência, que segundo Rosanvallon (1997), desenvolve-se "aos saltos" mediante crise social pondo em causa a coesão da sociedade ou diante de conflito militar suscitando o problema de sua sobrevivência. No exemplo apresentado, tratava-se de crise social a ser resolvida por meio da expansão de oportunidades de escolarização.

Nessa mesma direção, mas com ênfase na profissionalização, Nilo Peçanha (1867-1924), ainda como Presidente do Estado do Rio de Janeiro (1903 - 1906), estava atento às questões que diziam respeito à formação dos trabalhadores. Dizia o governante que o ensino deveria ser

menos theorico e mais pratico. Também já é tempo do legislador fluminense voltar a sua attenção para as escolas profissionaes e agrícolas, em que fizemos não um povo de lettrados e de burocratas, mas uma sociedade de trabalhadores (PEÇANHA, 1904, p. 10. In: Mensagem do Presidente do Estado do Rio de Janeiro).

Diante dessa circunstância, Nilo Peçanha salientava que instituir escolas profissionais era uma "necessidade pública”. Para reforçar seu pensamento acerca dessa necessidade, recorreu à experiência que viveu na França.

Como na França, - tive ocasião de dizer na Camara dos Deputados, quando mereci a honra de ser representante do Rio de Janeiro ao Congresso, - o Brasil mudou duas vezes de constituição, desthronou dous imperadores, proclamou o regime republicano, libertou o trabalho, mas no que diz respeito á formação propriamente do novo povo nada se tem feito. Succedem-se os programmas e as reformas, mas o espírito do ensino ainda é o mesmo. 0 que infelizmente seduz os Estados ainda é a organização de Academias; os moços sahem das Faculdades mantidas pelos Governos para continuar na vida pratica a disputar e a esperar tudo das graças e dos favores do Estado; sahem em geral, das Academias, desarmados para a lucta da vida, sem o sentimento da própria responsabilidade e da independência individual, não podendo ser úteis muitas vezes, nem a si, nem á família, nem ao paiz. No Rio de Janeiro a creação de escolas profissionaes e agricolas corresponderiam hoje a uma alta necessidade pública. (PEÇANHA, 1904, p. 10. In: Mensagem do Presidente do Estado do Rio de Janeiro. Grifos meus). 
Cinco anos após esse pronunciamento, em 14 de junho de 1909, Nilo Peçanha assumiu a presidência da República. Estavam criadas, assim, as possibilidades para que o governo federal incluísse também no ensino profissional regular, a assistência pela profissionalização em todo o território nacional. Nessa ocasião, foram criadas 19 Escolas de Aprendizes Artífices, instituídas uma em cada Estado, pelo decreto federal n 7566, de 23 de setembro de 1909, expedido pelo presidente Nilo Peçanha. 0 aspecto referente ao caráter assistencial dessas escolas diz respeito ao seu Artigo $6^{\circ}$, no qual se previa, preferencialmente, a matrícula de menores "desfavorecidos da fortuna". No Estado do Rio de Janeiro foi fundada uma Escola de Aprendizes Artífices na cidade de Campos (CUNHA, 1980, p. 27).

Nesse cenário de mudanças, indaga-se: de que forma os governantes se organizaram para operacionalizar a assistência asilar/escolar à criança desvalida na cidade do Rio de Janeiro?

\section{EQUACIONAMENTO DO PROBLEMA DOS DESVALIDOS: CONHECER PARA PROVER}

Duas foram as condições para que o Estado equacionasse a assistência pela profissionalização: conhecer quem precisava ser assistido e implementar as instituições.

Em relação à primeira condição, Rosanvallon (1997) trabalha com a hipótese de que o desenvolvimento da probabilidade estatística possibilitou ao Estado protetor /providência "gerir os riscos e os acasos com a mesma facilidade com que gere as regularidades a que está acostumado" (ROSAVALLON, 1997, p.23). Essas novas técnicas de gestão de populações que teriam sido engendradas pelos economistas foram definidas por Foucault (1979, p. 292) como governamentalidade, ou seja, podem ser compreendidas como a "arte de governar", em que era preciso produzir dados sobre a população para intervir nas suas regularidades (natalidade, focos epidêmicos, número de mortos, de vacinados, por vacinar, etc.), inclusive até o ponto em que se evitassem as sedições, as guerras.

Nesse sentido, no Brasil, a estatística passou a ser um importante instrumento técnico do governo. No Estado do Rio de Janeiro, a criação dos serviços estatísticos oficiais ocorreu ainda nos tempos de Província e, portanto, remonta a 1850. Essa notícia está presente no Relatório apresentado por seu vice-presidente, João Manuel da Silva, à Assembleia Legislativa desta Província, no ano de 1857, na parte que trata da Repartição do Arquivo Estatístico.

No entanto, a Lei do Censo nacional só foi criada em 1870; no ano seguinte, foi formada a primeira instituição estatística do Brasil, a Diretoria Geral de Estatística, e, em 1872, foi realizado o primeiro censo geral do país, quando foram registrados 9.930 .478 habitantes (FARIA FILHO, 2002. p.133). Regionalmente, o serviço de recolhimento e sistematização dos dados estatísticos também foi realizado. Tratando-se do Rio de Janeiro, Schueler (2002) observa que o censo de 1872, ao fazer

\footnotetext{
o mapeamento do perfil sócio-econômico e habitacional das freguesias desta cidade confirma as análises de historiadores, que já ressaltaram a significativa heterogeneidade e a complexidade da sociedade imperial - não sendo possível reduzi-la à dicotomia casa-grande e senzala - nas últimas décadas do século XIX. Do ponto de vista ocupacional, entre a população livre o Censo de 1872 apontava uma grande quantidade de pessoas classificadas como "sem profissão": 92.106. Ou seja, 38,61\% representando uma categoria que compunha certa variedade de ofícios, como carregadores, ambulantes, artesãos autônomos e trabalhadores pobres. Entre os empregados domésticos, havia cerca de 20.000 indivíduos, com grande percentual de mulheres e crianças. Nas demais profissões classificadas encontravam-se: $63,86 \%$ de "trabalhadores braçais"; $36,14 \%$ "artesãos oficiais"; $8,54 \%$ de comerciários e comerciantes; $10 \%$ de "proprietários e capitalistas", 4,8\% de profissionais liberais (incluindo 897 professores e homens de letras) (SCHUELER, 2002, p. 51).
} 
Em tempos republicanos, o prefeito da cidade do Rio de Janeiro, Pereira Passos (1836-1913), estabeleceu, por meio do Decreto Municipal no 441, de 26 de junho de 1903, o Ofício Geral de Assistência destinado à organização da estatística geral de todos os estabelecimentos e instituições de assistência, públicos e privados. Ao poder público caberia a fiscalização ou

superintendendo-os, sem, aliás, quebrar a completa autonomia das associações e estabelecimentos já existentes. Havia, nesse acto, prudente e opportuna disposição determinando que, como providência preliminar e base imprescindível á execução do programma e á acção fundamentada desse orgão propulsor, o prefeito mandasse organizar desde logo a estatística geral de todos os estabelecimentos de caridade e assistencia, quer públi$\cos$, quer privados. Semelhante medida significava que um recenseamento de conjuncto, em que se recolhem números exactos e informes seguros, constituindo um estalão necessário para o perfeito conhecimento de toda e qualquer organização harmonica e solidária. Devia ser a pedra de toque para a planeada composição, visando as obras de socorro e previdencia sociais (PAIVA, 1922, p. X. Grifos do autor).

Quanto ao trabalho de levantamento da estatística geral dessas instituições de caridade existentes no Rio de Janeiro, foi encomendado ao Juiz da Corte de Apelação, Ataulpho de Paiva (1867 - 1955), na gestão de Pereira Passos. Por meio do Decreto n. 1.001 de 13 de novembro de 1914, o governo municipal criou, em caráter permanente, a comissão Especial de História e Estatística da Assistência Pública e Privada. Segundo Ataulpho de Paiva, esta seria uma "providência preliminar e base imprescindível para a acertada solução do problema social da assistência" (PAIVA, 1922, p. 15). Ainda segundo Ataulpho de Paiva (1922, p. 1012), foram necessários dois anos para realizar o trabalho cujos dados estatísticos foram atualizados até os anos de 1920; portanto, dois anos antes da publicação do trabalho em 1922, sob o título "Assistência Publica e Privada no Rio de Janeiro (Brasil). História e Estatística”. Foram recenseadas 624 instituições e os dados, organizados em mapas e quadros. 0 tom da crítica ao poder público municipal também esteve presente no trabalho de Ataulpho de Paiva. Para o jurista, muito pouco merece ser registrado. Municipalidade e Governo Federal quase nada tem feito que deva ser referido com applausos. Nesta materia a prefeitura tem se furtado a tomar a mais leve e simples iniciativa com relação aos menores do sexo masculino. As duas unicas casas de assistencia - o Asylo de Meninos Desvalidos e a Casa de São José - vieram para às mãos do governo do municipio por força de leis especiaes que lhe transferiu o encargo que pesava sobre o Ministerio do Império do antigo regimen (PAIVA, 1922, p. 9)

Dessa forma, justificou seu trabalho historicamente, ao recuar ao período imperial. Nesse sentido, no âmbito da ação oficial que criara o Asilo de Meninos Desvalidos, Ataulpho de Paiva entendia que aquele

\section{acto tem uma elevada siginificação}

que deve ser posta em relevo. Elle deixa patente que o elemento conservador, prepoderante na epocha, não exitou em proclamar o dever que imputava ao Estado proteger a infancia desamparada e, com isso, o de resolver o problema da assistencia social na sua effectividade direta. Nos tempos que correm chamar-se-hia a isso pomposamente - o socialismo do Estado. Mas o argumento não se perderá como elemento histórico. Valerá por sua alta significação e mostrará aos theoricos da escolastica impenitente que, no seio da nossa tradição e da propria legislação pátria, o intervencionismo do Estado nos assumptos de solidariedade social não constitui novidade alguma (PAIVA, 1922, p.9).

Na opinião de Ataulpho de Paiva (1922), fora o abandono de crianças, a quem lhes faltava o trato e a educação, que motivara D. Pedro II "a corrigir esse mal creando-lhes os asylos que suprissem o lar ou que thes dessem o que o lar lhes negava”. Havia nessa afirmativa "o dever que se reconhecia o governo de proteger a infância desamparada, dando-lhe asylo" (PAIVA,1922, p. 479-480). Como criar condições favoráveis para transformar tal reconhecimento em realidade? Como vimos no Brasil império houve abertura de instituições de proteção à infância pobre. No caso da municipalidade do Distrito Federal, o trabalho encomendado a Ataulpho de Paiva é indício da preocupação dessa instância de poder em relação à proteção aos "necessitados", incluindo a criança desvalida, como veremos a seguir. 


\section{AÇ̃̃O DO ESTADO PROTETOR: A CASA DE SÃO JOSÉ/INSTITUTO FERREIRA VIANNA E O IPJA}

Tanto a Casa de São José/Instituto Ferreira Vianna quanto o IPJA funcionaram em regime de internato e integraram a assistência pública escolar, organizada e mantida pelo governo do Distrito Federal, concretizando a participação do Estado em políticas de assistência escolar. Entretanto, o investimento do Estado não visava a ocupar o lugar da beneficência privada ou inibir iniciativas deste tipo (RIZZINI, 1993, p. 91). Dessa forma, a circulação da infância pobre pelos espaços dessas instituições, no período em análise, foi um item dividido entre o poder público e/ou filantropos e a própria demanda dos pais, tios, avós e/ou tutores por ela responsáveis (RIZZI$\mathrm{NI}$ e MARQUES, 2012), como demonstrado nos requerimentos à matrícula apresentados no início deste artigo.

Iniciemos pela iniciativa do poder público. Nesse caso o exemplo é do IPJA. Um estabelecimento pensado e estruturado para funcionar como casa, escola e oficinas, de modo a abrigar, educar e profissionalizar menores desvalidos em regime de internato. Ressalta-se que a formação completa dos alunos do IPJA foi prevista para acontecer em seis anos e abrangeria os cursos de Ciências, Letras, Artes e Profissional.

Em relação ao público-alvo teriam preferência à matrícula jovens comprovadamente pobres na faixa etária compreendida entre os 12 e 15 anos de idade (art, $5^{\circ}$. Coleção de leis municipais, 1897, p.170). A lista dos documentos exigidos para comprovação do desvalimento e, portanto, garantia de matrícula era extensa: certidão de idade, atestados médico e de pobreza; aprovação no exame de admissão, em que os candidatos à vaga fariam provas de Português (ditado e leitura) e Matemática (prática das quatro operações) (art. $7^{\circ}$ ). Seriam dispensados do exame aqueles meninos que apresentassem certificados de "estudos primários do primeiro grau” (Parágrafo único). Pelo regulamento de 1894, os menores internos em estabelecimentos de assistência ao menor desvalido teriam prioridade para a matrícu- la, desde que "revelassem aptidão para o aprendizado profissional”(Coleção de leis municipais, 1897, p.171).

Encerradas as aulas, iniciariam os exames finais em Bancas, comissões compostas por professores, que seriam nomeados por decreto após concurso (art. 77), sendo presidida pelo diretor do IPJA (art. 15). Esses exames constariam de

\begin{abstract}
Prova escripta e oral para as cadeiras do curso de sciencias e lettras; de prova graphica para as de caligraphia e desenho: de prova pratica para as de musica e gymnastica. $\mathrm{O}$ aproveitamento das demais aulas será julgado à vista dos trabalhos feitos durante o anno pelos alumnos (Coleção de leis municipais, 1897, p.171 e segs.).
\end{abstract}

Segundo o artigo 20, do regulamento de 1894, os exames dos alunos seriam julgados pelas notas reprovado, aprovado simplesmente, plenamente e com distinção. Em termos mais específicos, havia as seguintes notas: de 1 a 5 (aprovado simplesmente); de 6 a 9 (aprovação simples); 10 (aprovado com distinção). Os alunos aprovados receberiam "um título que os habilitava ao exercício de uma profissão”.

É interessante destacar que o trabalho acontecia nas diversas oficinas cuja venda dos produtos garantia, por um lado, parte da manutenção do IPJA e, por outro, depósito de $10 \%$ do trabalho de cada uma das oficinas, os quais eram divididos, proporcionalmente, pelos alunos das mesmas oficinas. A parte que competia aos alunos seria recolhida à Caixa Econômica cujo resgate seria feito por ocasião de seu desligamento do IPJA. Aliás, o aluno que fosse desligado por mau procedimento perderia o direito ao saldo de sua conta corrente.

Em relação ao "regime disciplinar" do IPJA, em todos os Regulamentos consultados, foram previstas: repreensão particular e em público; privação do recreio ou de passeio, com trabalho; e, por fim, a expulsão. Para inspeção geral do IPJA, havia os Inspetores que tinham o cargo de polícia do Instituto a ser exercida a juízo do diretor, como previsto, por exemplo, no regulamento de 1897. 
A esse cenário, acrescenta-se que, pelo decreto $n$. 2.940 de 22 de novembro de 1927, art. 565, qualquer aluno interno que fosse suspenso por indisciplina três vezes em um ano seria desligado e não poderia mais ser matriculado em estabelecimento congênere. A título de registro, em nenhum dos regulamentos consultados, encontrei a expressão “castigo físico”. Essa ausência já sinalizava mudanças na legislação educacional, cujos debates questionavam a eficácia dos castigos físicos nas escolas públicas, desde meados do século XIX.

Já as iniciativas, cujos mantenedores foram o poder público e filantropos, a Casa de São José é exemplar. Foi fundada no Rio de Janeiro em caráter particular, em 09 de agosto de 1888, pelo Ministro da Justiça Antônio Ferreira Vianna (1833-1903), após constatar, pessoalmente, as precárias condições de vida das crianças recolhidas ao Asilo de Mendicidade e já denunciadas pela imprensa (MACHADO, 2004, p.3).

A Casa de São José constituiu-se num estabelecimento organizado para proteger meninos desvalidos de 6 a 12 anos de idade, em regime de internato. Tinha por objetivo proporcionar-lhes educação primária, abrangendo os aspectos da educação física, moral e cívica. Inicialmente, abrigou 100 meninos, sendo que, em 1922, esse número subiu para 400 meninos (RIZZINI, 1993, p. 154). Nos seus primeiros anos de funcionamento, foi dirigida por irmãs de caridade e "sustentada pela generosidade do povo", visto que, no começo de sua existência, não tinha apoio oficial, o que veio a ocorrer somente em 1890. Pelo Decreto de $n^{0} .657$, de 12 agosto, passou à jurisdição do Ministério do Interior, sendo transferida para a municipalidade em 1893 e incorporada à Diretoria Geral de Higiene e Assistência Pública. Em 1902, por meio do Decreto n. 282, de 27 de fevereiro, a Casa de São José passou a fazer parte dos estabelecimentos de ensino profissional mantidos pela prefeitura e seu ensino constituiria um curso de adaptação ao IPJA (SILVA, 1936, p. 198).

A interseção com o IPJA pode ser demonstrada, também, pelo movimento de matrículas: do total de matrículas da Casa de São José - 1.964 alunos - des- de a sua inauguração até 1915, 602 alunos, ou seja, $37 \%$ foram transferidos para o IPJA.

\section{Gráfico 1 - Movimento aeral da Casa de São José Movimento Geral da Casa de São José 1888-1915}

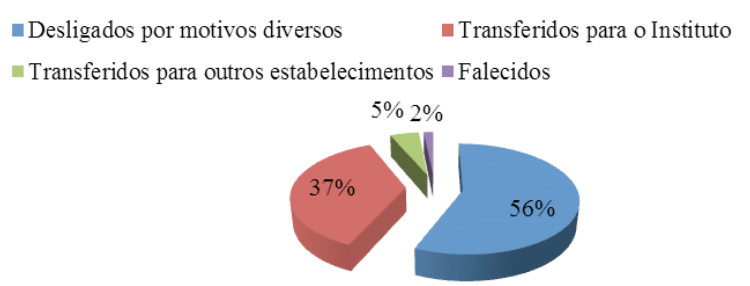

Fonte: Relatório anual do diretor da Casa de São José (CEMETEFV).

Pelo Decreto 1.030, de 05 de janeiro de 1916, a Casa de José foi transferida para a Diretoria Geral de Instrução Pública e transformada em escola mista. Manteve o regime de internato, recebendo meninas e meninos de 5 a 8 anos de idade. Nesse mesmo ano, em 14 de março, por meio do Decreto 1.061, recebeu a denominação de Instituto Ferreira Vianna, em homenagem ao seu fundador (FONSECA, 1986, p. 227-228). A partir daí, as meninas que completassem 10 anos e os meninos que atingissem 11 anos de idade seriam desligados e transferidos, respectivamente, para os Institutos Profissionais Feminino/Orsina da Fonseca e masculino/IPJA (SILVA, 1936, p. 200). No entanto, de acordo com Marques (1996, p. 58), o menino cujo comportamento fosse considerado irregular seria transferido para a Companhia de Aprendizes Marinheiros, mediante solicitação do Diretor ao Ministro do Interior.

No ano de 1927, através do Decreto $n^{\circ}$. 3.281, de 23 de janeiro de 1927, que regulamentou "o ensino técnico profissional",

foi estipulado que o Instituto Ferreira Vianna manteria o seu caráter de instituto de assistência social, como internato para menores, sem prejuízo de seu programa educativo. $\mathrm{O}$ Instituto Ferreira Vianna seria, a um tempo, estabelecimento de ensino primário elementar e 
médio, de 5 anos, e um instituto de assistência social à infância desamparada. Para internamento de menores e a matrícula no curso primário, seria exigida a idade mínima de sete anos completos e máxima de oito anos. Do Instituto Ferreira Vianna, só poderiam ser transferidos para o Instituto Profissional João Alfredo [...] os alunos que obtivessem o certificado de exame de final do curso primário (SILVA, 1936, p. 202).

Com base nesses termos, percebe-se que laços entre a Casa de São José/Instituto Ferreira Viana e o IPJA foram estabelecidos desde a sua inauguração, em 1888, quando o IPJA ainda funcionava como um Asilo de Meninos Desvalidos. Considerando que, com o advento dos anos 30, foram transferidos, em 20 de março daquele anos, para o IPJA 10 alunos do Instituto Ferreira Vianna, antiga Casa de São José, por terem terminado o curso primário, pode-se acreditar que os vínculos entre essas duas instituições foi uma constante durante toda a Primeira República.

\section{CONSIDERAÇÕES FINAIS}

A associação educação e trabalho tem sido uma alternativa histórica para conferir validade a crianças pobres e abandonadas. A partir desse entendimento, destaquei a assistência pela profissionalização voltada para os jovens identificados como desvalidos a partir da noção de Estado protetor. As medidas adotadas pelo Estado, ou seja, as políticas educacionais e assistenciais elaboradas para minimizar o problema das crianças e dos jovens desvalidos nos anos iniciais da República, foram concretizadas com a criação de escolas profissionais. Dessa forma, do universo das quatro escolas profissionais masculinas existentes no Distrito Federal, no período em análise, destaquei a Casa de São José, posteriormente Instituto Ferreira Vianna, abrigo escola para crianças desvalidas até os 12 anos de idade e o IPJA que ministrou o ensino profissionalizante aos jovens pobres de 12 a 15 anos de idade.

Essas instituições funcionaram, na maior parte do tempo, normatizadas pelos regulamentos do ensino profissional do Distrito Federal. Dessa forma, da análise desses regulamentos, foi possível evidenciar a assistência aos filhos dos pobres sob a ótica da profissionalização, a partir do Decreto $n^{0} 282$ de 27 de fevereiro de 1902. Nesse sentido direcionei o foco para a particularidade dessas instituições no que se refere ao funcionamento em regime de internato e à dupla função: a de abrigo e a de escola de ensino elementar e profissionalizante. Remeto-me principalmente ao Decreto de 1902 que constituiu o principal referente da política de proteção às crianças e jovens pobres do Distrito Federal, pois normatizou o funcionamento dessas instituições asilares/escolares em conexão com a política educacional (educação física, ensino primário elementar e profissional, trabalhos manuais), com a higiene (inspeção médica asilar/escolar) e com a assistência social escolar (estabelecimentos com funcionamento conectado).

Nesse sentido, observa-se que parte das iniciativas desenvolvidas pela municipalidade, do então Distrito Federal, expressou a marca das necessidades de uma determinada parcela da população, formada por crianças e jovens desvalidos, que se acreditou poderem ser resolvidas por meio da ação de um Estado protetor.

No entanto, apesar dos esforços governamentais, a prática que visava conjugar educação e trabalho, para o referido grupo social, foi uma meta difícil de ser cumprida. No IPJA parte considerável do alunado não completou a formação. Essa constatação poderia ter sido um fator considerável de redução de oportunidades diversas daqueles jovens? Não é possível responder essa questão afirmativamente, pois, após dois anos e meio de estudos no IPJA, Antônio Fonseca se empregou "como torneiro mecânico no Lloyd, no ano de 1911”, (Pasta 1911005 AF.AAMD) Já Nelson Vieira, matriculado em 1911, após três anos de estudos no IPJA, iniciou "no commercio a lucta pela vida"( Pasta 1911 - LA-WA 020 NV - AAMD). Comparecem também outros argumentos para justificar a retirada do jovem do IPJA antes de concluir os estudos, como "por ser seu único filho homem" (Pasta 1925- HCS 
056- AAMD). E ainda uma mãe que por acreditar que o filho não suportaria "os trabalhos physicos que naquelle Instituto the obrigam, pede a Va.Sa . o immenso favor de mandar excluil-o (Pasta 1925 - AO 028. AAMD). Dessa forma, garantir a permanência do aluno no IPJA foi um problema que também marcou presença nas escolas regulares do Distrito Federal, como demonstrado pelo estudo de Paulilo (2007).

\section{REFERÊNCIAS}

\section{Documentos}

Correspondências recebidas (de 16 de janeiro de 1929 a 24 de dezembro de 1930). Pastas RCR 021, 1911; OCC 084, 1920; 073 MST, 1924; HCS 056 e AO 028,1925 .

Coleção de leis municipais e vetos do Distrito Federal. Rio de Janeiro, (1892-1894). Organizada por Alvarenga Fonseca, Tipografia do Jornal do Commércio, 1897.

Lei No 8.069, de 13 de julho de 1990. Disponível em: http://www.planalto.gov.br/ccivil/LEIS/L8069.htm. Acesso em abril de 2014.

Lei n 10.219, de 11 de abril de 2001. Disponível em: http:// www3.dataprev.gov.br/SISLEX/paginas/42/2001/10219. htm. Acesso em abril de 2014.

Relatórios Ministeriais e Provinciais. Disponíveis em: http://www.crl.edu/pt-br/brazil Acesso em abril de 2014.

Relatório Anual do diretor da Casa de São José. Centro de Memória da Escola Técnica Ferreira Viana - CEMETEFV.

\section{REFERENCIAS}

CUNHA, Beatriz Rietmann da Costa e. Assistência e profissionalização no Exército: elementos para uma história do Imperial Colégio Militar. In: SIMPÓSIO NACIONAL DE HISTÓRIA, 24., 2007, São Leopoldo, RS. Anais do XXIV Simpósio Nacional de História - História e multidisciplinaridade: territórios e deslocamentos. São Leopoldo: Unisinos, 2007. CD-ROM.

CUNHA, Luiz Antônio. A formação escolar da força de trabalho industrial no Brasil: as Escolas de Aprendizes Artífices. Fundação Getúlio Vargas. Relatório de pesquisa, 1980. Mimeo.

FONSECA, Celso Suckow da. História do ensino industrial no Brasil. Rio de Janeiro: Escola Técnica Federal,1986. 5v.

FOUCAULT, Michel. Microfísica do poder. 7 ed. Tradução de Roberto Machado. Rio de Janeiro: Graal, 1979.

GONDRA, José G.. A sementeira do porvir: higiene e infância no século XIX. Educ. Pesquisa. 2000, vol.26, n.1 p. 99-117.

GONDRA, José Gonçalves; SCHUELER, Alessandra. Educação, poder e sociedade no Império Brasileiro. Sao Paulo: Cortez, 2008.

GOUVÊIA, Maria Cristina Gouvêia, JINZENJI, Monica. Escolarizar para moralizar: discursos sobre a educabilidade da criança pobre (1820-1850). Revista Brasileira de Educação, v. 11, n.31 jan./abr., 2006.Disponível em: http://www.scielo.br/pdf/rbedu/v11n31/ a09v11n31.pdf Acesso em junho de 2013.

KUHLMANN, Jr. Moysés. A circulação das ideias sobre a educação das crianças; Brasil, início do século XX. In: FREITAS, Marcos Cezar de, KUHLMANN, Jr. Moysés (Orgs.). Os intelectuais na história da infância. São Paulo: Cortez Editora, 2002, p. 459-503.

LIMA, Solange Silveira. "Recrutá-los jovens": A formação de aprendizes marinheiros em Sergipe e Lisboa 
(1868-1905). 2013. 109 p. Tese (doutorado em educação). Faculdade de educação. Universidade Federal de Minas Gerais, Belo Horizonte.

MACHADO, Vilma Alves. A casa de São José. Instituição fundada por Ferreira Viana, em 1888 no Rio de Janeiro, para abrigar e educar crianças desvalidas para o trabalho. Dissertação de Mestrado. Rio de Janeiro, 2004. Universidade Estadual do Rio de Janeiro.

PAIVA, Ataulpho Nápole de. Assistência pública e privada no Rio de Janeiro: história e estatística. Rio de Janeiro: Typografia do Annuario do Brasil. 1922.

PAULILO, André Luiz. A estratégia como invenção: as políticas públicas: as políticas públicas de educação na cidade do Rio de Janeiro entre 1922 e 1935. 2007. Tese (Doutorado em Educação) - Faculdade de Educação, Universidade de São Paulo, São Paulo, 2007. Disponível em: <http://www.teses.usp.br/teses/disponiveis/48/48134/tde-03052007-110357/>. Acesso em: 2014.

RIZZINI, Irma. Educação popular na Amazônia Imperial: crianças índias nos internatos para formação de artífices. In: SAMPAIO, Patrícia; ERTHAL, Regina (Org.). Rastros da memória: histórias e trajetórias das populações indígenas na Amazônia. Manaus: EDUA/ CNPq, 2006.

RIZZINI, Irma; MARQUES, Jucinato de S. Os incorrigíveis da cidade: um estudo sobre a distribuição e circulação das infâncias na Capital Federal (décadas de 1900 e 1910). In: LOPES, Sonia; CHAVES, Miriam (org.). A História da Educação em Debate: Estudos comparados, profissão docente, infâncias, família e igreja. Rio de Janeiro: MAUAD/FAPERJ, 2012.

RIZZINI, Irma. Assistência à Infância no Brasil: uma análise de sua construção. Rio de Janeiro, RJ: Ed. Universitária Santa Úrsula, 1993.
ROSANVALLON, Pierre. A crise do Estado-providência. Goiânia: Editoras UnB e UFG, 1997. Trad. de Joel Pimentel de Ulhôa.

SILVA, Octacílio Augusto. 0 ensino popular no Distrito Federal. Rio de Janeiro, Oficina Gráfica da Secretaria Geral de Educação e Cultura, 1936.

SCHUELER, Alessandra de. Forma e culturas escolares na cidade do Rio de Janeiro: representação, experiência e profissão docente nas escolas públicas primárias - (1870-1890). Rio de Janeiro: Tese de Doutorado, UFF, 2002.

SCHUELER, Alessandra F. Martinez de. Crianças e escolas na passagem do Império para a República. Rev. bras. Hist., São Paulo, v. 19, n. 37, Sept. 1999. Disponível em: http://www.scielo.br/scielo. Acesso em 23 de julho de 2013.

SOUZA, Maria Zélia Maia de. Educar o jovem para ser "útil à si e à sua Pátria": a assistência pela profissionalização, Rio de Janeiro (1894-1932).Tese de Doutorado em Educação. Universidade Federal Minas Gerais, 2013.

SOUZA, Maria Zélia Maia de. Educar, trabalhar e civilizar no Asilo de Meninos Desvalidos (1875-1894): caminhos possíveis. Dissertação de Mestrado em Educação. Universidade Federal do Estado do Rio de Janeiro - Unirio, Rio de Janeiro, 2008.

VEIGA, Cynthia Greive. História da Educação. São Paulo: Ática, 2007.

1. 0 presente trabalho é parte de pesquisa realizada para tese de doutorado em educação. Educar o jovem para ser "útil a si e à sua Pátria”: a assistência pela profissionalização, Rio de Janeiro (1894-1932). Universidade Federal de Minas de Gerais, 2013.

2. Doutora em Educação e professora substituta da Universidade do Estado do Rio de Janeiro, Faculdade de Educação. E-mail: zeliammaia@yahoo. com.br. 